\title{
Sciendo
}

Administration, vol. 69, no. 3 (2021), pp. 79-92

doi: 10.2478/admin-2021-0021

\section{Strengthening the structures to support research for public policy in Ireland}

\author{
Mary Doyle \\ Visiting Research Fellow in Public Policy, Trinity Long Room Hub, \\ Dublin, Ireland
}

For a national research endeavour to be successful there needs to be an effective dialogue and understanding between research scientists, politicians and the public, so that policies and strategies are in place to bring about research that benefits society, and that society will support ... This requires effective working between these organisations and sectors, and a compact that bonds science and society, which will both deliver excellent science and ensure that it is used for the public good. (Nurse, 2015, p. 8)

\section{Introduction}

The core theme of the paper is the importance of developing a framework of actions to support more aligned activity in the national research landscape in support of public policy in Ireland - a need which has been highlighted by the Covid-19 pandemic. The paper traces the evolution of policy and investment in research in Irish higher education over recent decades and considers in particular the structures which have been put in place to support this effort. It then 
considers and identifies a number of key themes and priorities for future consideration and discussion. It suggests that in order to make progress on this agenda, action needs to be initiated, led and managed in three distinct but overlapping spaces: in the research community itself, and particularly in the higher education institutions (HEIs); in our institutions of democracy, specifically the Oireachtas and government departments; and in the combined efforts of the research funders. Then all three must design an architecture which enables them to engage positively with each other into the future. Finally, the paper suggests some practical steps in building and strengthening the structures for dialogue between the various stakeholders, drawing on both national and international experience and practice.

The Covid-19 pandemic has demonstrated the immense resources and expertise within the Irish academic research base that can be drawn upon to inform public policymaking and decision-making for the public good, right across the wide range of issues which a government must address as it seeks to chart a way forward and solve complex problems in the short, medium and long term.

In a webinar organised by the Irish Universities Association (IUA) and the Royal Irish Academy (RIA) in June 2020 on the subject of 'Evidence Informed Policy Making - The Role of Higher Education and Research', Professor Philip Nolan, President of Maynooth University and Chair of the National Public Health Emergency Team (NPHET) Irish Epidemiological Modelling Advisory Group, described a phone call he received from the Chief Medical Officer, Dr Tony Holohan, right at the very start of the Covid-19 pandemic, in early 2020. In that phone call, Dr Holohan asked him what was available by way of research and expertise in Ireland to contribute to managing the pandemic. This was on a Sunday morning and by the following Wednesday a diverse team had been assembled, mobilising a wide range of expertise - no mean achievement for a small country with limited resources.

The role of NPHET has been central to crafting the Irish response to the pandemic and, while not without criticism on a number of fronts, it has provided a strong, expert and stable platform on which information is analysed and recommendations made to government based on available knowledge and expertise.

Making a number of observations based on that experience, Professor Nolan stressed the importance of maintaining a broad base of expertise in the country, ensuring that this expertise base is funded and rewarded for engagement with policy and that people are 
supported and encouraged to engage in active dialogue with a diverse set of individuals and networks - both nationally and internationally. He noted that expert research capacity had been built by a focused and sustained investment over decades through the national funding structures. Importantly, the absorptive capacity of the public service to deal with complex issues is high since many policymakers are graduates of the higher education sector. Finally, he pointed to the need to mobilise the expertise of the humanities as core contributors to the conversation.

This story represents a powerful and immediate case study, which shows what a small country like Ireland with big ambition can do when it draws on its diverse sources of expertise; the value of concerted action; the importance of getting it right for our society; and the need to continue to make the system better so that it can achieve its potential and support Ireland's future well-being.

As the Covid-19 pandemic has demonstrated, the need for reliable research, evidence and thinking that can inform public debate and policy has never been greater. Covid-19 is just one area of complex national policy which needs input from multiple disciplines and a wide range of perspectives. There are many others. In this age of social media, with the rapid emergence of different forms of knowledge production and mass communication, this is an important issue which urgently requires attention.

\section{Looking back: Some context}

Societal challenges are typically highly complex, and the engagement of researchers from both Arts, Humanities and Social Sciences, and Science, Technology, Engineering and Maths can often generate more innovative solutions and new ways of approaching and thinking about problems. Targeted initiatives of different scales are required to cultivate and grow quality interdisciplinary research that can deliver optimal impact. (Department of Business, Enterprise and Innovation, 2015, p. 44)

It is useful to recall the original ambition for research investment in Ireland and trace its evolution over recent decades, in order to consider the next steps in its ongoing development. Three themes are particularly relevant in this context: 
- evolution of policy;

- investment;

- building the national architecture for research.

\section{Evolution of policy}

Guiding the early development of building the Irish research ecosystem was a series of important policy documents, which included the Technology Foresight Ireland reports by the Irish Council for Science, Technology and Innovation in 1999 and the Strategy for Science, Technology and Innovation, published in 2006 by the Department of Enterprise, Trade and Employment when the current Taoiseach, Micheál Martin, TD, was minister in that department. This latter strategy was a landmark document, which devoted an entire chapter to research in the public sector. In the chapter on implementation, emphasis was placed on the structures for taking a whole-ofgovernment approach, and it added that 'it is important to ensure that our investment in excellent research also has regard to economic and social needs and that these should play a guiding role in where investments are made' (Department of Enterprise, Trade and Employment, 2006, p. 83).

Other key national strategies followed which have guided developments in this area since then - principally the National Strategy for Higher Education to 2030 (Department of Education and Skills, 2019), the associated Higher Education System Performance Framework (Higher Education Authority (HEA), n.d.) and Innovation 2020 (Department of Business, Enterprise and Innovation, 2015). However, the connection to public policy is not articulated as a key component in the same way as, for example, the skills pipeline or building the research capacity with the enterprise sector has been - although one could argue that it is of similar importance. This may be changing, however, as the Mid-term Review of Innovation 2020 (Department of Business, Enterprise and Innovation, 2019) noted that interdisciplinary research could be encouraged further to deliver economic and/or societal impact and that coordination between research and innovation performers and policymakers could be explored further. The recently published consultation paper by the Department of Further and Higher Education, Research, Innovation and Science (DFHERIS) (2021) on the new Research and Innovation Strategy 2021-27 also identifies these themes.

This shift towards interdisciplinary research and addressing societal challenges is also seen in the evolution of the European framework programmes, most importantly with the Horizon Europe programme. 


\section{Investment in research}

Underpinning as it does the overall research ecosystem in the higher education sector, it is important to acknowledge at the outset that in calculating the core grant allocation, the HEA has always intended that a proportion of that funding be used to support basic research in HEIs. The scale of the investment in basic research from this source can sometimes be taken for granted, but it is the foundation on which initiatives like the government's Programme for Research in Third Level Institutions (PRTLI) build.

The major step change in the level of investment in research in Ireland can be traced back to the PRTLI, which was launched in 1998. PRTLI provided integrated financial support for institutional strategies, programmes and infrastructure to ensure that HEIs had the capacity and incentives to formulate and implement research strategies to give them critical mass and world-level capacity in key areas of research. The period from 2001 to 2009 was one of major research investment, growth and development. However, the onset of the financial crisis in 2008/9 halted the momentum for development which had been built up. In more recent times, investment has grown again but at a much slower pace than in earlier periods - with resultant implications for the level of growth and performance across the system. In a recent Irish Times interview, on 24 June 2021, the Taoiseach, Micheál Martin, noted this trend and indicated that he sees the need for a 'step-change' in third-level funding to promote research upon which, he argues, the foundation for future economic success can be built (Leahy, 2021).

\section{Building the national architecture for research}

To support this investment, much important research agency architecture has been built over the period, including the establishment of the Irish Research Council (IRC), Science Foundation Ireland (SFI) and Knowledge Transfer Ireland (KTI). All these agencies, taken together, have played a vital role in building up the Irish research ecosystem through investments at both institutional and individual researcher level. A strong focus has been placed on supporting greater collaboration across the system, building on strengths and identifying opportunities. In other sectors, the work of Enterprise Ireland (EI), the Health Research Board (HRB) and Teagasc, among others, is a key contributor to the overall research ecosystem. 
Conversely, since the Advisory Council on Science and Technology was wound down some years ago, Ireland has been in the minority globally in not having some sort of advisory research council for science.

In the higher education sector itself, there was continued growth in both the university sector and the technological sector, including the development of strong new institutional models such as technological universities. This has resulted in a strong and engaged research system across the higher education sector with examples of good policy connection, but these are not brought together in a way that makes them easily accessible to policymakers and other communities. The work of, for example, the Geary Institute in University College Dublin, the Department of Government and Politics in University College Cork, and the All-Island Research Observatory (AIRO) in Maynooth University, as well as the pathfinding at the former Policy Institute in Trinity, illustrates the potential which exists to enrich the dialogue.

On the government side, the Irish Government Economic and Evaluation Service (IGEES) and the Library and Research Service of the Houses of the Oireachtas, among other innovations such as departmental statements of strategy and research and data strategies, are important building blocks in this context also.

The challenge and opportunity now is to build further on these developments and to support greater structured engagement between the policy and the research communities.

\section{Key themes emerging and priorities for action}

The creation of a single department encompassing further and higher education, research, innovation and science has changed the policy landscape. Universities, with their role in transitions from further education, with their development of talented and rounded individuals that contribute to the knowledge economy and an inclusive society, with their strong research base, with their reach into knowledge transfer and innovation, are uniquely placed to shape and benefit strongly from this new integrated approach. (Harris, 2020)

In approaching this complex agenda, it is helpful to identify a number of key themes and priority areas for action which can act to support the discussion to identify and focus on a number of key issues. In this section, I would identify the following priority themes: 
- creating a unified system;

- knowledge management and knowledge brokering;

- importance of thinking about policy relevance in the mechanisms of research funding.

\section{Creating a unified system}

Although a very impressive higher education structure has been built in Ireland over the past thirty years, it has tended to be discipline, academic and institution oriented. It has been less focused on developing the sort of linkages in the system which would support a structured dialogue both within and between the research and policy communities. This is true of both the scientific advisory community and the arts, humanities and social sciences (AHSS) disciplines.

On the practical side, there are very few, if any, organised intermediate structures where expertise (particularly in the arts and humanities) has any systematic interaction with other disciplines in developing policy advice - for example, environmental researchers interacting with arts and humanities researchers. Within the thirdlevel sector there are very few places where scholars develop systematic interactions with policy as an integral part of their personal and professional development or where subject-specific research is combined with knowledge-intensive interdisciplinary cooperation.

A core question now is how to support the Irish research ecosystem to operate to its potential in the light of where we came from and where we want to go as a society, and how the Irish research ecosystem can support the realisation of wider national objectives.

The recent establishment of the DFHERIS, led by Minister Simon Harris, TD, which brings together previously separate elements of the research ecosystem in Ireland, does indeed represent an important opportunity for greater alignment and investment focus in this sector.

\section{Knowledge management and knowledge brokering}

One of the issues which has become clear in the Irish context is that there is a need for a more systematic approach to knowing what research is being carried out in Irish universities and the academic research community. Currently, it is difficult to get a line of sight on the research activity in HEIs - between different institutions, different disciplines, and different projects and programmes. It is not possible for Irish policymakers or indeed any other interested parties to discover what research is being undertaken in Ireland and where and how it is being undertaken. The potential for evidence-based 
policymaking and for the societal impact of Irish research is severely constrained when basic information about the existence of the research is not accessible.

Another important aspect of this issue is the question of knowledge brokering. It is one thing to know what and where research is being undertaken. It is quite another to be able to forge links and relationships to join the research and the policymaking worlds. A systematic focus on building the architecture to do this is vital. In Ireland, Campus Engage has been an important resource in this arena, having published a very helpful series of policy briefings for civil servants and policymakers, HEIs and funding agencies on engaged research for impact. Also, the success of KTI in highlighting the economic impact of research may be a useful model. KTI adopted a systematic and strategic approach and, critically, had national support from the top. People were placed on the ground in the HEI technology transfer offices to broker connections between the research community and the enterprise base, and they entered into contracts with the HEIs for delivery of targets. There could be lessons from this initiative perhaps in relation to the policy arena.

There certainly seems to be potential in the Irish context to consider how best to design a collective interface on the lines of the above, starting perhaps with the policy-facing parts of the Irish HEI landscape, such as those mentioned earlier.

\section{The importance of thinking about policy relevance in the mechanisms of research funding}

How we design the programmes, calls and evaluations from the various funding streams at the national level plays a central role in deciding on what research gets prioritised and funded. It is worth giving some specific consideration to the issues that arise in this context.

There are a number of streams of funding for research in Ireland, but they can be broadly categorised as institution-specific funding, national research funding in respect of specific disciplines (IRC, SFI, HRB, EI, etc.), EU funding and philanthropic funding. From the outside looking in, there appears to be a multiplicity of funding programmes aimed at different disciplines and different times of the research career life cycle, from early career researchers to experienced principal investigators. In a small country, it should be possible to think about a much better alignment of the funding on a strategic basis to support researchers at all stages of their careers, to support a broad 
base of research in the country, to better align the programmes (and perhaps simplify them), to align the timing of calls and, all round, to make the system easier to understand and navigate. Again, this is an area where the new department could take an important initiative.

\section{Next steps: Developing the structures for dialogue}

In order to take these themes forward and to prioritise action, the next essential step is to deepen the relationship between policymakers and the research community, which is vitally necessary to tackle the wideranging policy challenges that have been identified. This paper makes a number of recommendations for action but, firstly, it identifies a number of overarching considerations which can provide a systemwide perspective on this work. In this section, I identify and discuss the following issues:

- adoption of underpinning principles;

- developing the structures for dialogue.

\section{Adoption of underpinning principles}

What to do with this complex agenda in a complex landscape? It is clear that making progress requires concerted action on the part of a number of actors - specifically, academics, policymakers and funders. As these worlds intersect, each group needs to better understand the world of the other.

The starting point is that there is still little structured dialogue between the academic community and policymakers. To make progress on this agenda, action needs to be initiated, led and managed in three distinct but overlapping spaces: in the research community itself, and particularly in the HEIs; in our institutions of democracy, specifically the Oireachtas and government departments; and in the combined efforts of the research funders. Then all three must design an architecture which enables them to engage positively with each other.

In order to support more unity of purpose in progressing this work, I would suggest that a core set of underpinning principles be adopted by the key actors on the lines set out below:

- Ireland's research expertise represents a significant national strategic asset. 
- Enhancing the modes of connectivity and dialogue across the research and policy communities will significantly strengthen the quality and depth of the knowledge and insights available to policymakers charged with responding to complex policy challenges.

- Strong and profitable research-policy networks require access to a broad base of expertise.

- The Public Service Reform and Civil Service Renewal frameworks, the Higher Education System Performance Framework, and the National Research and Innovation Strategy are existing mechanisms through which research-policy engagement can be incentivised.

- A high-functioning, effective research-policy relationship requires a strong architecture with a clarity of leadership, roles, objectives, and tools.

\section{Developing the structures for dialogue}

To make progress on this agenda, action needs to be initiated, led and managed in three distinct but overlapping spaces: in the research community itself, and particularly in the HEIs; in our institutions of democracy, specifically in the Oireachtas and in government departments; and in the combined efforts of the research funders. All three actors must design an architecture which enables them to engage positively with each other. Suggested priorities within each are outlined below.

\section{Research community and HEIs}

- Put a stronger spotlight on the relationship with policymaking as a core part of the mission of the higher education sector.

- Consider how the emerging Researcher Career Framework can include a specific focus on the policymaking relationships.

- Support academics across their career to engage with the policymaking system through a more formalised approach to induction, coaching and mentoring by senior academics with a track record in this field.

- Consider the design of incentives and rewards for academics in the higher education system as part of the overall approach.

- Design specific training for academics on how to engage with government.

System-wide, there is a need for a more integrated approach with the objective of harnessing the collective research power and expertise of the sector to make it easier for policymakers to draw on it to support 
their deliberations. Perhaps a good starting point would be to think about how best to organise more formal interaction between the various policy-facing institutes and centres of expertise which have been developed in the Irish higher education system over the years. The IUA, Technological Higher Education Association (THEA), technological universities and the RIA all have an important leadership role to play in this context.

\section{Government and the Oireachtas}

- Require all government departments to identify and include within their published statements of strategy a short statement on areas of research interest, which would serve to tell the research community in an accessible way the pressing policy questions that are live in the system.

- Allied to this, there needs to be a focused investment in developing policy capacity in the system, particularly building on the work of the IGEES but broadened to include other disciplines. In this context, there is value in considering how to build two-way secondments between policymaking and academia.

- The Oireachtas has developed several successful initiatives to build research-policy relationships, and these learnings can be drawn upon in the development of a whole-of-system approach. It would be very useful to have a dialogue about these various initiatives and to think how, taken together, they would support a more strategic national approach to building the relationships between research and policy.

\section{Public research funders}

- The HEA has an important role to play as it manages the core funding for the higher education system. The System Performance Framework should, on the next review, include more extensive material to support the connect between research and policy.

- The design and evaluation of public research funding calls, particularly those from the major public research funders, fundamentally influence the shape and nature of the overall national research effort. Complex societal, scientific and environmental challenges require research and collaboration across a range of disciplines.

- As the need for greater collaboration across government increases to address a myriad of policy challenges, there is also a need for researchers to engage across disciplines, where there has been 
reluctance in the past. Developing appropriate funding mechanisms to support and encourage such engagement is an important issue for funders.

- When defining, designing and evaluating calls, research funders should adopt a collective approach to ensuring that a broad base of research and all research career stages are supported and that the timing of calls is aligned to make the system easier to navigate.

\section{Conclusions - Implementation challenges and the vital role of leadership}

In this final section I want to say a word about implementation. A former colleague of mine famously coined the acronym IDD implementation deficit disorder. Her point was to highlight that when a strategy was written or a decision was taken to proceed in a certain way, insufficient attention was paid over the longer term to see that the actions which had been committed to had indeed been taken. This is particularly difficult when the ownership for achieving the various objectives become more and more distributed. That is why putting in place a strong focus on implementation over a sustained period is both so important and so challenging in the policy context.

Ireland's ambition in establishing a high-performing research ecosystem that delivers advice for policy can be scaled up in accordance with our geopolitical position in the world. First, there is a clear domestic agenda for change based on stronger alignment right across the Irish research ecosystem. Second, there are potential benefits to an all-island approach to building relationships, working together to strengthen the overall research base and to identify and address shared policy issues. Finally, our goal should be to maximise the impact of Irish research in a wider European and global setting. The need - and, indeed, the opportunity - to do so has become more urgent in the post-Brexit world when valuable UK contributions to formulating policy positions, particularly in an EU and global context, will no longer be available. We need a more robust, integrated and self-reliant system to accomplish this aim.

Therefore, the initial first step of starting a conversation on the central importance for Ireland of building and supporting the relationships between the research and policymaking communities is a vital one. This dialogue will require strong and sustained leadership from a number of particularly important players: the DFHERIS, 
together with the HEA, IUA, THEA, RIA, the national research funders and national contact points, and government departments. The establishment of the DFHERIS provides a vital foundation for this strong and sustained leadership. The recently announced consultation by the DFHERIS on the new Research and Innovation Strategy for Ireland and the associated consultation paper provide an excellent opportunity to move forward the necessary conversations.

The prize of a strong national research infrastructure which is well connected to the world of policymaking is an important one for Ireland and one that should be within our grasp if we can begin to reimagine and weave together the important pieces which Ireland has built over a long period into a stronger whole.

\section{References}

Department of Business, Enterprise and Innovation. (2015). Innovation 2020: Ireland's Strategy for Research and Development, Science and Technology. Retrieved from https://enterprise.gov.ie/en/Publications/Innovation2020.html [6 July 2021].

Department of Business, Enterprise and Innovation. (2019). Mid-term review of Innovation 2020. Retrieved from https://enterprise.gov.ie/en/ Publications/Publication-files/Mid-term-Review-of-Innovation-2020.pdf [6 July 2021].

Department of Education and Skills. (2019). National Strategy for Higher Education to 2030. Retrieved from https://www.gov.ie/en/publication/ 072a65-national-strategy-for-higher-education-to-2030/ [6 July 2021].

Department of Enterprise, Trade and Employment. (2006). Strategy for Science, Technology and Innovation. Retrieved from https://enterprise.gov. ie/en/Publications/Publication-files/Forf\%C3\%A1s/Strategy-for-ScienceTechnology-and-Innovation-2006-2013.pdf [6 July 2021].

Department of Further and Higher Education, Research, Innovation and Science. (2021). National Research and Innovation Strategy 2021-27 consultation paper. Retrieved from https://www.gov.ie/en/ publication/a526a-national-research-and-innovation-strategy-2021-to2027-consultation-paper/ [6 July 2021].

Harris, S. (2020). Keynote by Simon Harris TD at IUA Future of Ireland seminar series webinar. Retrieved from https://www.gov.ie/en/speech/14a93keynote-by-simon-harris-td-at-iua-future-of-ireland-seminar-serieswebinar/ [6 July 2021].

Higher Education Authority. (n.d.). Higher Education System Performance Framework. Retrieved from https:/hea.ie/funding-governanceperformance/managing-performance/system-performance-framework/ [6 July 2021]. 
Irish Council for Science, Technology and Innovation. (1999). Technology Foresight Ireland: An ICSTI overview. Retrieved from https://enterprise. gov.ie/en/Publications/Publication-files/Forf\%C3\%A1s/ TechnologyForesight-Ireland.pdf [6 July 2021].

Leahy, P. (2021, June 24). Micheál Martin interview: 'Mistakes get made in a pandemic'. The Irish Times.

Nurse, P. (2015). Ensuring a successful UK research endeavour: A review of the UK research councils. Retrieved from https://www.gov.uk/government/ publications/nurse-review-of-research-councils-recommendations [6 July 2021]. 